\title{
Development of microstructure during deformation of carnallite and bischofite in transmitted light
}

\author{
JANOS L. URAI \\ Institute of Earth Sciences, State University of Utrecht, P.O. Box 80.021, 3508 TA Utrecht (The Netherlands)
}

(Received September, 1985, revised version accepted June 6, 1986)

\begin{abstract}
Urai, J.L., 1987. Development of microstructure during deformation of carnallite and bischofite in transmitted light In: H.J. Zwart, M. Martens, I. van der Molen, C.W. Passchier, C. Spiers and R.L.M. Vissers (Editors), Tectonic and Structural Processes on a Macro-, Meso- and Micro-Scale. Tectonophysics, 135: 251-263.

During deformation of $5 \times 5 \times 0.1 \mathrm{~mm}$ samples of carnallite and bischofite in transmitted light, the development of the microstructure was followed by time-lapse photography. In dry samples, carnallite deforms by mechanical twinning, intracrystalline slip and by cataclastic processes. The addition of brine strongly enhances dynamic recrystallization by progressive misorientation of subgrains and by grain boundary migration. Bischofite shows similar behaviour, in agreement with results from samples deformed in a triaxial apparatus. Important microstructural processes during dynamic recrystallization of wet bischofite are grain coalescence, grain dissection and grain migration. The oscillatory motion of grain boundaries and sudden large changes in grain boundary migration rate were important features.
\end{abstract}

\section{Introduction}

Deformation of crystalline materials in thin section is a useful technique for studying the microstructural changes during deformation which later observation will not reveal. Detailed studies using this technique (Means, 1983; Tungatt and Humphreys, 1981, 1984; Jessell, 1986) have considerably improved our understanding of dynamic recrystallization in particular (Urai et al., 1986).

In this paper, an investigation of the microstructural changes during deformation of carnallite $\left(\mathrm{KMgCl}_{3} \cdot 6 \mathrm{H}_{2} \mathrm{O}\right)$ and bischofite $\left(\mathrm{MgCl}_{2}\right.$. $6 \mathrm{H}_{2} \mathrm{O}$ ) is reported. The results provide a useful check on the interpretation of microstructures found in samples of these materials, which had been deformed in a triaxial apparatus (Urai, 1983, 1985). In addition, a study of the microstructural processes during ongoing dynamic recrystallization was made, and some details of the "catastrophic" changes in grain-boundary migration (Poirier and Guillopè, 1979) could be studied.

\section{Experimental procedures}

The apparatus used is a modified version of the one described in Urai et al. (1980). It consists of a metal block, holding the sample-piston assembly, and a ram to drive the piston (Fig. 1). The sample-piston assembly consists of two glass plates between which the sample, gasket and pistons (these are all exactly $0.1 \mathrm{~mm}$ thick) are clamped. Experiments were carried out at temperatures between 20 and $150^{\circ} \mathrm{C}$ (constant to within a few degrees), and with a constant piston displacement rate, resulting in strain rates around $10^{-5} \mathrm{~s}^{-1}$. Through an aperture in the metal block the sample was viewed in transmitted light, and the development of the microstructure was followed by time-lapse photography. 


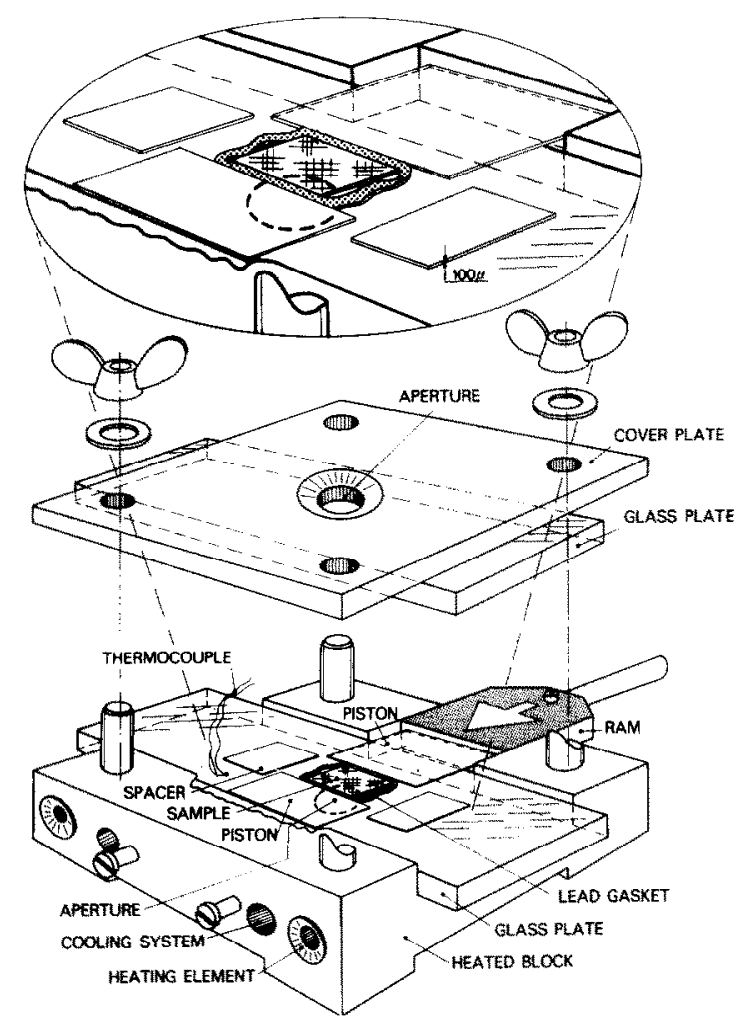

Fig. 1. Schematic drawing of the apparatus for deforming samples in thin section.

Samples of single and polycrystalline material were made by polishing small blocks of material on one face, cutting a rectangular net of grooves into this surface, and fixing it to a glass plate with wax, together with $0.1 \mathrm{~mm}$ thick steel spacers. Samples were then ground to the thickness of the spacers, and removed from the glass. All specimen preparation was carried out at relative humidities below 20\%. Samples were then, with or without the addition of a few vol.\% saturated solution of the material, placed between the glass slides, which were lubricated with a thin layer of silicone oil. To achieve a good seal, the surface of the lead gasket was coated with a thin layer of silicone rubber. (This gasket was used with varying success in experiments above $50^{\circ} \mathrm{C}$, to prevent otherwise rapid evaporation of brine.)

\section{Observations on carnallite}

Starting material for these experiments was a coarse-grained carnallite from the Veendam salt pillow (Coelewij et al., 1978; Urai and Boland, 1985), from which single crystalline samples, containing occasional small halite or kieserite grains, were produced. Deformation usually started with mechanical twinning. Twin lamellae mostly nucleated at the edges of the sample or at halite inclusions; they had parallel boundaries and usually extended from one end of the sample to the other. Twinning often went to completion in large parts of the sample (Fig. 2). Lattice bending and cracking were the only additional deformation mechanisms in samples deformed without added brine, up to $150^{\circ} \mathrm{C}$ (carnallite melts incongruently at about $170^{\circ} \mathrm{C}$; see Kern and Franke, 1981).

Samples deformed with added brine showed markedly different behaviour. Between $60^{\circ}$ and $130^{\circ} \mathrm{C}$, lattice bending was soon followed by the development of subgrains, progressively misorienting with strain. Above misorientations of around 15 degrees, (subgrains could be called individual grains then), their boundaries started migrating at a rate of around $0.01 \times 10^{-6} \mathrm{~m} / \mathrm{s}$, producing equiaxed new grains of about $0.05 \mathrm{~mm}$ in diameter (Fig. 3). Another important source of new grains were former twin boundaries. Migration of these could result in the formation of linear arrays of new grains, or in the consumption of the whole twin by the host. Pre-existing cracks oriented at high angles to the compression direction were often healed by recrystallization. In one sample which was deformed at $100^{\circ} \mathrm{C}$ and subsequently heated to $130^{\circ} \mathrm{C}$, rapid $\left(0.2 \times 10^{-6} \mathrm{~m} / \mathrm{s}\right)$ grain boundary migration resulted in larger new grains of about $0.1 \mathrm{~mm}$ diameter. At strains of about $30 \%$, between 10 and $30 \%$ of the samples were replaced by new grains.

\section{Interpretation}

Keeping in mind the absence of confining pressure in the present experiments, the microstructural development observed is in good agreement with the microstructures found in carnallite deformed in a triaxial apparatus (Urai, 1985). In both cases, dry samples deformed by intracrystalline slip and twinning, accompanied by cataclasis. In samples deformed in the presence of brine, recrystallization and ductility were strongly en- 
hanced, which is in agreement with results reported by Kern and Franke (1986). The process of recrystallization in the present experiments consisted of the progressive misorientation of sub- grains until high-angle grain boundaries were formed and of the subsequent "slow" (see e.g. Drury et al., 1985) migration of these boundaries, and of the migration of former twin boundaries
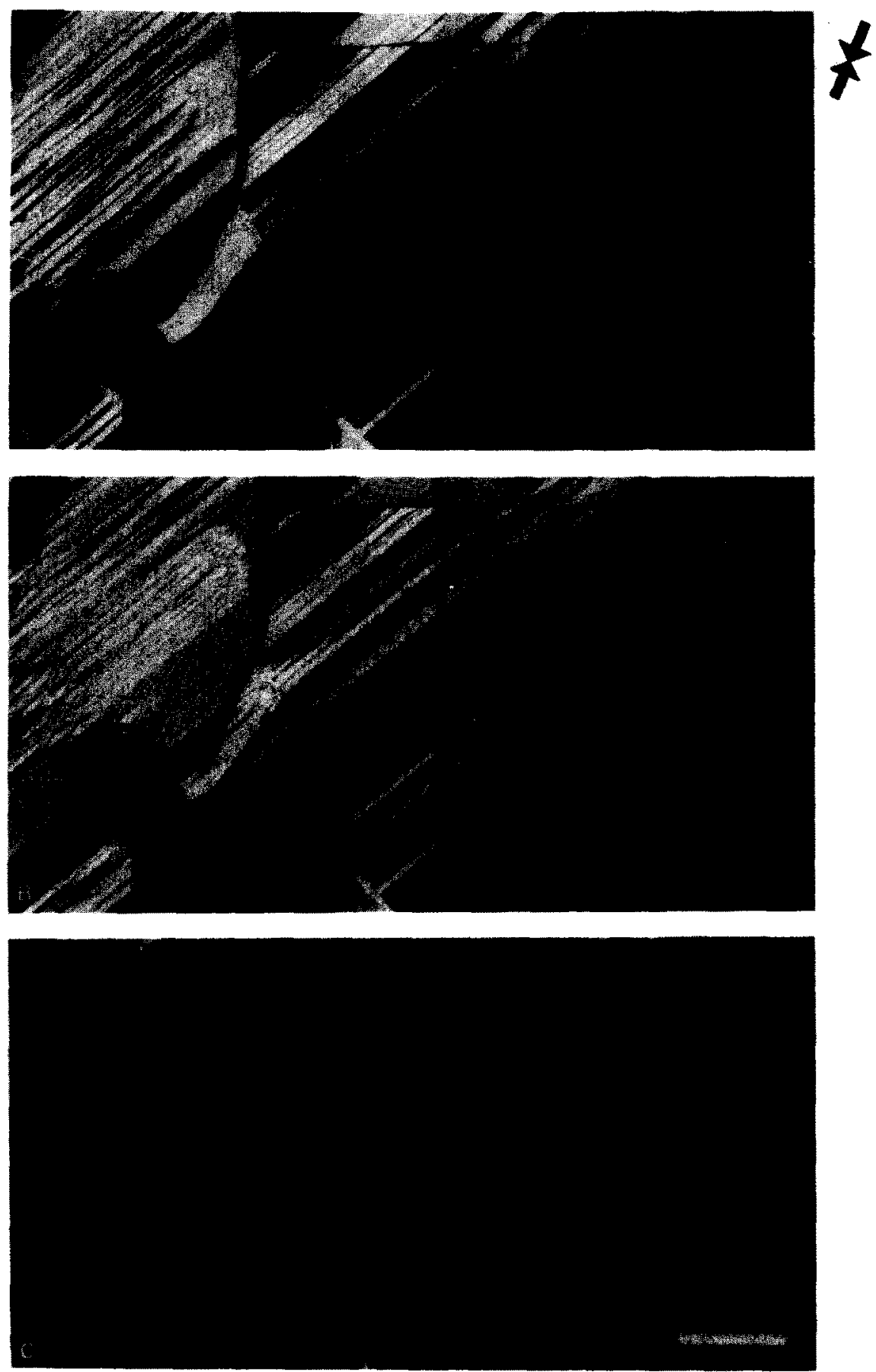

Fig. 2. Mechanical twinning in a carnallite sample containing cracks and a halite inclusion. Note twinning going to completion in top left part of the sample. Dry sample, $T=150^{\circ} \mathrm{C}$, crossed polarizers, scale bar is $0.5 \mathrm{~mm}$. 
(which became irrational by deformation). Because the starting material in the present experiments consisted of single crystals, grain boundary

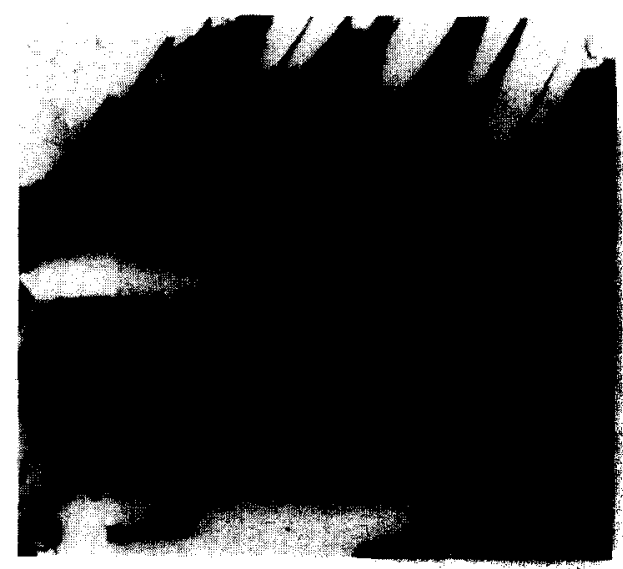

37

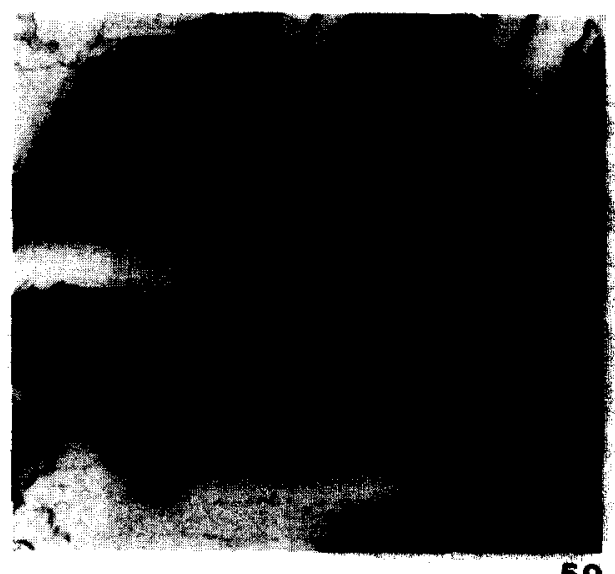

59

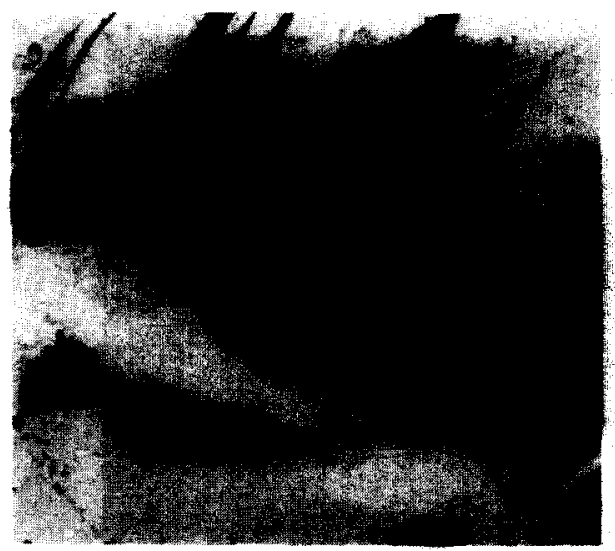

129 migration started operating at higher strains than in the polycrystalline samples described in Urai (1985), where high-angle grain boundaries were

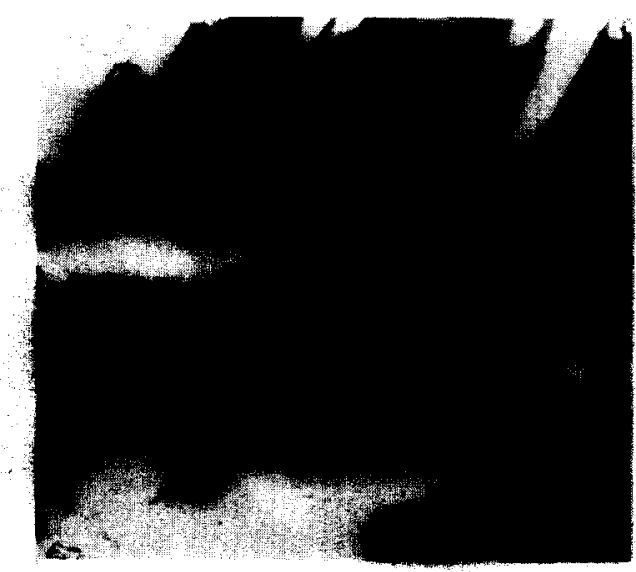

51

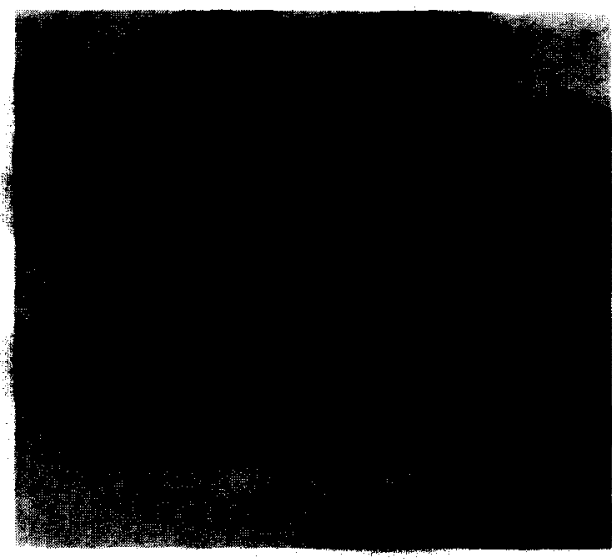

102

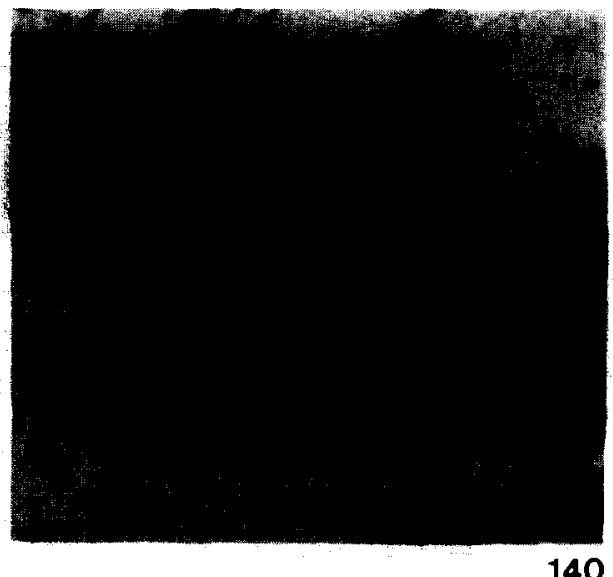

Fig. 3. In-situ sequence illustrating microstructural development in wet carnallite. Note progressive misorientation of subgrains. followed by migration of grain and twin boundaries and healing of a crack by recrystallization. $T=100^{\circ} \mathrm{C}$, crossed polarizers, scale bar is $0.5 \mathrm{~mm}$. Strain rate was $5 \times 10^{-5} \mathrm{~s}^{-1}$. Numbers indicate time (in minutes) after the start of the experiment. 
present in the starting material.

As was argued in Urai (1985), the reason for the difference in behaviour between samples deformed with and without brine is thought to be a slight change in $\mathrm{H}_{2} \mathrm{O}$ concentration in the carnallite lattice, and the presence of thin brine films on grain boundaries. It should also be noted that, in addition to the higher temperatures, the presence of relatively short diffusion paths (because thin samples with a relatively rough surface were used in the present experiments), may explain the presence of twin boundary migration in the relatively fast see-through runs.

\section{Observations on bischofite}

\section{Dry samples}

At room temperature, the only processes observed were mechanical twinning (often going to completion), accompanied by lattice bending (see fig. 9b in Urai, 1983), and the development of cracks. Above $60^{\circ} \mathrm{C}$, small $(d \approx 0.05 \mathrm{~mm})$ new grains started growing in regions of strain concentration. Grain boundary migration rate $V_{\mathrm{gb}}$, which is defined here as the velocity of the interface along orthogonal trajectories, was around 0.2 $\times 10^{-6} \mathrm{~m} / \mathrm{s}$. Occasionally, rapid growth $\left(V_{\mathrm{gb}} \sim\right.$ $10^{-5} \mathrm{~m} / \mathrm{s}$ ) was observed, producing grains of $-0.2 \mathrm{~mm}$ diameter. Orientation of these was host-controlled: rapidly growing new grains in a large old one almost invariably had the same orientation. Between $60^{\circ}$ and $100^{\circ} \mathrm{C}, 30 \%$ shortening typically resulted in about $10 \%$ recrystallized material.

\section{Wet samples}

Dynamic grain-boundary migration was the most striking microstructural process in these samples, at all investigated temperatures. After about $20 \%$ strain, the samples were completely recrystallized, to a grain size independent of that of the starting material. Microstructure was clearly determined by deformation conditions: when deformation was stopped, metadynamic recrystallization resulted in a roughly fivefold increase in grain size in about a day. However, by rapidly

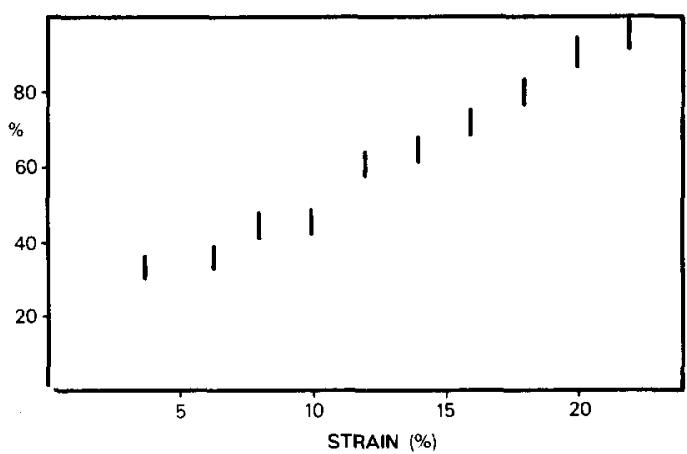

Fig. 4. Recrystallized fraction versus strain in the sample shown in Fig. 4. Note that in this experiment some grain boundary migration already took place before the start of deformation, probably because of some localized deformation of the sample during insertion into the rig.

cooling the samples to room temperature after deformation, the dynamic microstructure could be stabilized for several days.

One cine film, taken at 1 frame $/ 4 \mathrm{~s}$ from a wet sample deformed at $80^{\circ} \mathrm{C}$ and a strain rate of $\sim 5 \times 10^{-5} \mathrm{~s}^{-1}$, was selected for a detailed analysis of the dynamic recrystallization process. With an analytical projector, positions of grain boundaries were traced relative to gas bubbles serving as material markers. Because the position of grain boundaries oriented oblique to the line of sight could not be unequivocally determined, only grain boundaries oriented approximately parallel to the line of sight were used in the detailed analysis of grain boundary motion (see Figs. 9-11).

A trace of all discernible grain boundaries at several stages of deformation is shown in Fig. 5. The undeformed sample $(5 \times 5 \times 0.1 \mathrm{~mm}$ in size) consisted of three large grains, and a trail of smaller ones, grown on a scratch on the sample surface during preparation (see fig. 7 in Urai, 1983). Recrystallized fraction versus strain is plotted in Fig. 4. It can be seen that the sample completely recrystallized after about $20 \%$ strain, after which the grain size remained approximately constant. Recrystallized grains had irregular, amoeboid shapes and grain boundaries were lobate to serrated. The only discernible grain shape fabric was a weakly developed alignment of grain boundaries along directions oriented at 45 degrees to the compression direction. Such microstructures are thought to indicate a significant component of 

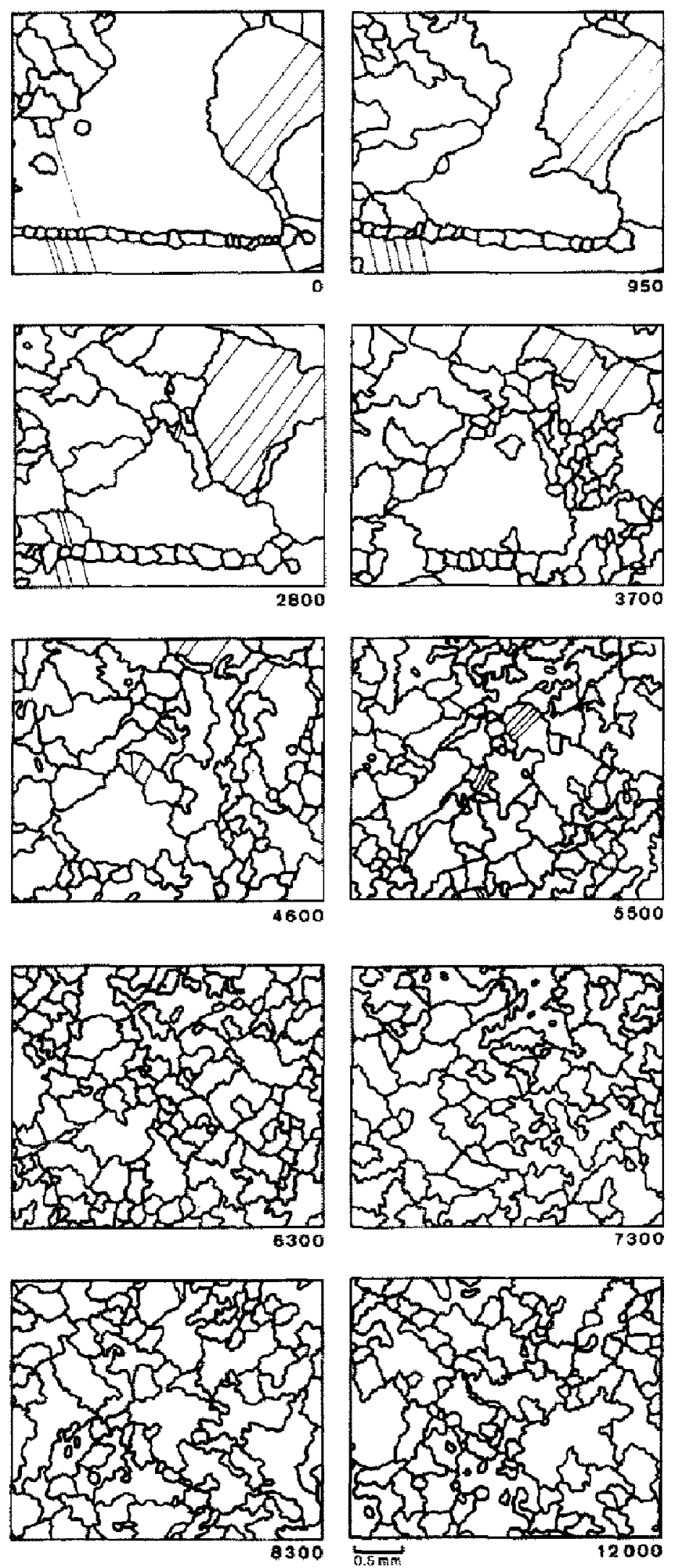

Fig. 5. Traces of all visible grain boundaries at several stages of deformation of a wet bischofite sample. Numbers indicate time in seconds after beginning of the experiment. Compression direction is approximately horizontal. Note that some of the larger "grains" at 5500,8300 and $12000 \mathrm{~s}$ were areas in optical extinetion and could have consistcd of scveral smaller grains. 
grain boundary sliding during deformation (Singh et al., 1973; Lister and Dornsiepen, 1982). Strain on the sample scale, as shown by displacement of several markers, was approximately homogeneous.

To get a better understanding of the microstructural processes that contribute to maintaining this semi-steady state microstructure (see also Means, 1981) the development of a number of selected grains was followed in detail.

Nucleation and growth of new grains, which later get deformed and consumed, was relatively unimportant in the development of microstructure. Rather, existing grain boundaries were continually sweeping through the microstructure,
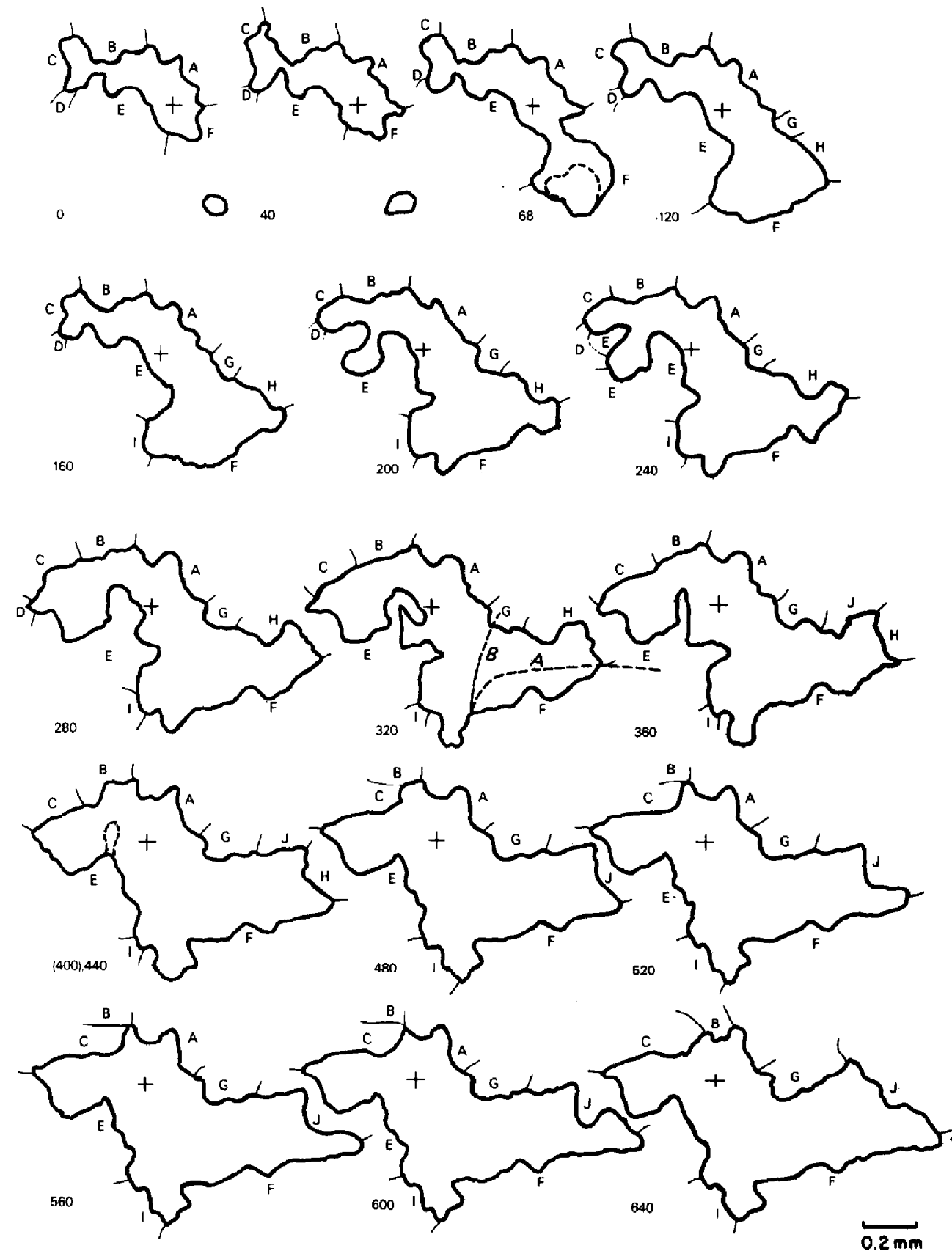

Fig. 6. A large new grain is being formed by coalescence of two grains in identical orientations, growing into grain $F$. Letters indicate different neighbour grains and the cross marks the position of a material marker. Numbers represent time (in seconds) after the start of the experiment. 
without the formation of new grains sensu stricto. (Note, however, that the character of a grain boundary changes drastically every time a "neighbour switch" occurs, i.e. when a grain boundary, migrating through a grain, encounters
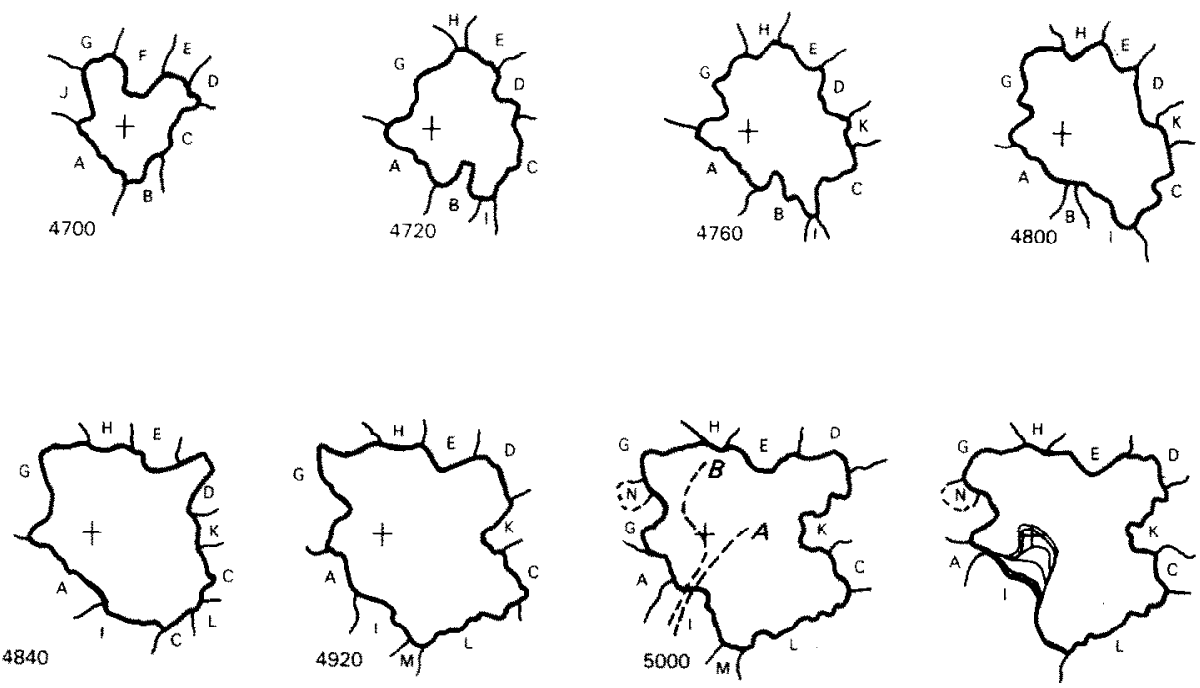

$5040 \quad 56,60,64,68,70$
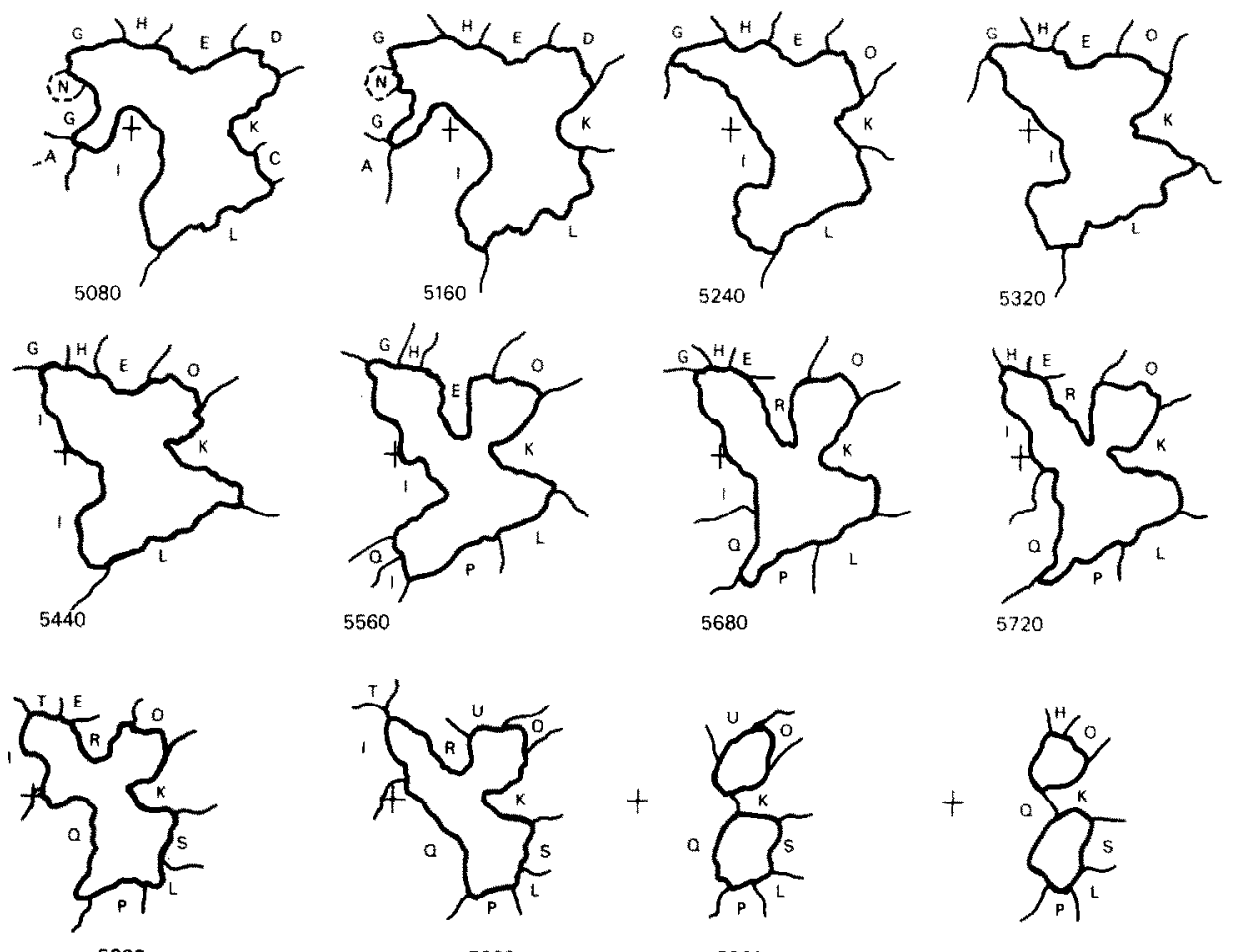

5880 another one). This gave rise to the following grain scale processes:

\section{(1) Grain coalescence}

Figure 6 shows two grains, which have nearly

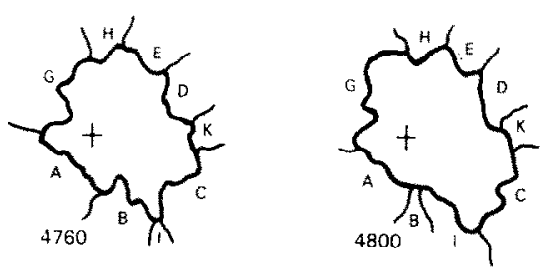


identical orientation, growing into a large old one. When these have grown to impingement, no grain boundary is formed between them and the two coalesce to form one grain. Coalescence was observed to be due to this "host control" effect, but also occurred in completely recrystallized material when grains in each others vicinity and with iden- tical orientations started growing towards each other.

\section{(2) Grain dissection}

Examples of this are shown in Figs. 7 and 8. This process occurs when a grain which is growing into its neighbour stops before the whole grain has

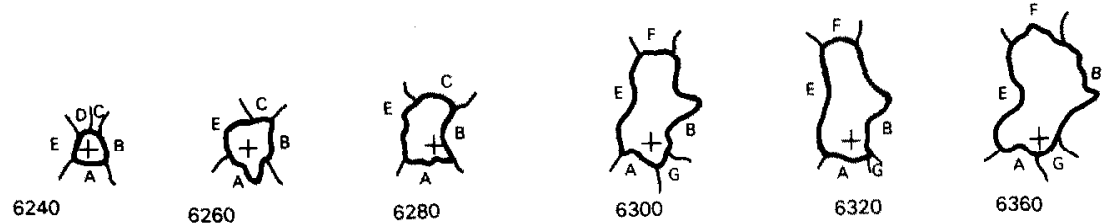

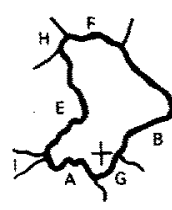

6440

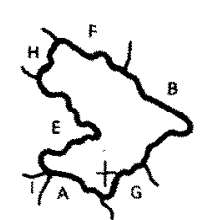

6560

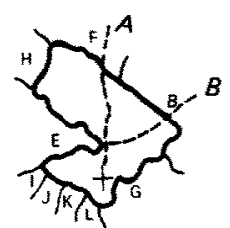

6720

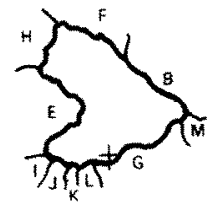

6800<smiles>[Y]C1CCCC(C)(C)CCCCC1(C)C</smiles>

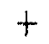

7480

7320

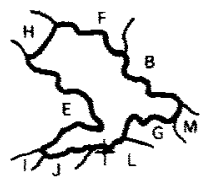

6820

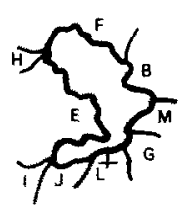

7000
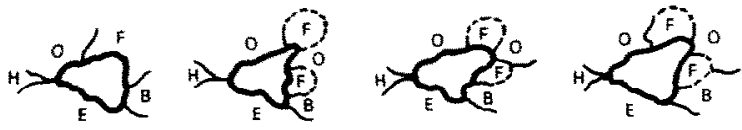

$8040^{+}$

$7720+7840 t$

$7920+$

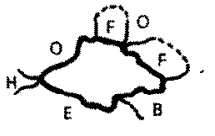

$+8080$
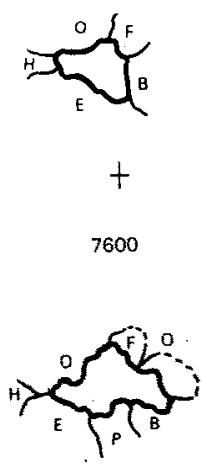

$+8200$
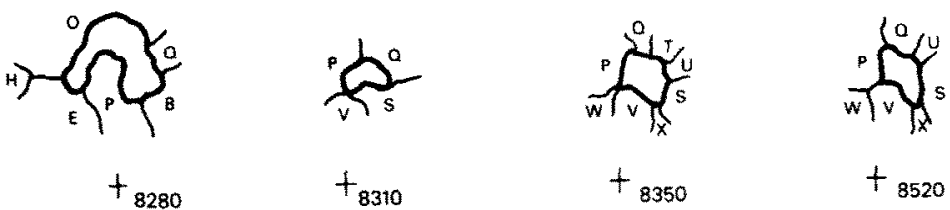

$+8240$

$$
t_{8280}
$$

8310

$+{ }_{8350}$

$t_{8520}$
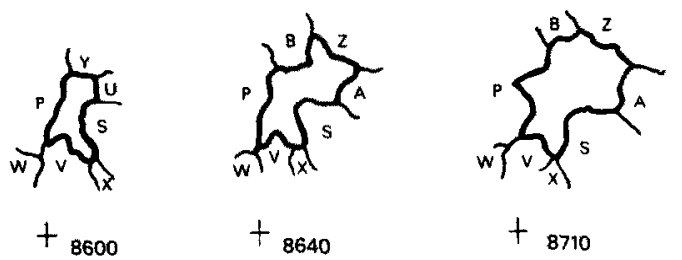

$+{ }_{8710}$
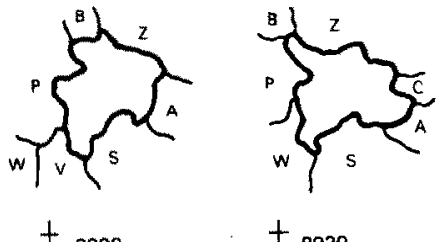

$+8920$

\section{$0.2 \mathrm{~mm}$}

Fig. 8. Cyclic changes in a grain's size, which can be seen to shift position with respect to the material marker it originally contained Symbols are the same as in Fig. 6. 
disappeared, producing characteristic "left-over grains" (see also Urai, 1983). It has been argued that grain dissection plays an important role in the development of "orientation families" (Urai, 1983; Urai et al., 1986), and it has been proposed by the above authors that this microstructure is diagnostic for dynamic recrystallization. It should be pointed out, however, that in the present experiments in which the sample is essentially two-dimensional, grain dissection probably occurs more frequently than in a bulk sample deformed under identical conditions.

(3) Grain migration, and cyclic changes in a grain's size

In Figs. 7 and 8, a grain can be seen to shift position with respect to a material marker it originally contained. By this process, despite the fact that most material domains are quite frequently swept by grain boundaries, a grain (= orientation domain, see Urai et al., 1986) can exist for relatively long periods and even undergo cyclic changes in its size, although after some time it may not contain any of the material which was originally within its boundaries (see also Means, (1983).

\section{(4) Progressive misorientation of subgrains}

Grains which have grown to a relatively large size with respect to their neighbours could of ten be seen to develop subgrains of about the same size as the smaller grains in the sample $(0.1 \mathrm{~mm})$. These increased their misorientation with strain and often became a new grain before being swept by a migrating grain boundary.

Finally, a number of interesting aspects of the grain boundary migration process will be described.

(a) Regions which had already been swept by a moving boundary once, were preferential sites for later grain boundary migration. It can be seen in Fig. 5 that while the remnants of the old grain recrystallize relatively slowly, regions of the sample which are already recrystallized can be swept by grain boundaries several times in the same time interval, although strain in the sample is fairly homogeneous. Although some strain concentra- tion in the recrystallized areas cannot be ruled out, in this case the interpretation that mobilities of grain boundaries migrating through recently recrystallized material are higher, is favoured. (Note that, as shown in Urai, 1983, migrating grain boundaries in wet bischofite contain thin brine films, from which the growing grain crystallizes. A change in, e.g., $\mathrm{H}_{2} \mathrm{O}$ defect concentration over this boundary is then quite conceivable).

(b) Grain-boundary migration rates can undergo large, sudden changes. Time-displacement curves of grain boundaries from Figs. 6, 7 and 8, along selected orthogonal trajectories are shown in Fig. 9. (Although only one material marker was followed in each case, these trajectories can be regarded as material lines, since strain during the periods of observation was low). The data points outlining the time-displacement curves represent selected frames from the film, and the connecting lines were drawn with the aid of visual inspection of intermediate frames. It should be noted in passing that the techniques used here do not have the resolution to reveal the very fine fluctuations in $V_{\mathrm{gb}}$ during migration through a fine substructure, described by Haessner and Hoffman (1978).

In Fig. 9A, after an initial period of no movement, the boundary starts moving at a rate of about $10 \times 10^{-6} \mathrm{~m} / \mathrm{s}$. After a certain amount of movement it slows down: on trajectory $B$ because it encounters another grain; on trajectory $A$, after slowing down, the boundary moves back a short distance. Such reversals of grain boundary migration direction were quite commonly observed throughout the experiment.

A similar sudden deceleration is seen in Fig. 9B, but in Fig. 9C the change is less sudden. Sudden accelerations of a migrating grain boundary do not necessarily occur: in Fig. 9D a boundary is shown to migrate at a more or less constant rate for a considerable time.

Sudden changes in grain boundary migration rate have been observed in several materials to date (see Urai et al., 1985, for a review), and have been interpreted to be associated with the "escape" of the boundary from its impurity atmosphere (Poirier and Guillopé, 1979). However, in wet bischofite grain boundaries have a fundamentally different structure from most metals and ceramics: 
they have been shown (Urai, 1983) to contain a fluid film several tens of nanometres thick. Therefore, the "catastrophic" changes in $V_{\mathrm{gb}}$ in the present work may not be interpreted in terms of the metallurgical models of impurity drag; al- ternative explanations have been given in Urai et al. (1986). In addition it should be noted that, in most of the cases reported to date (for both "wet" and "dry" grain boundaries), the sudden changes in $V_{\mathrm{gb}}$ were not essentially instantaneous, as im-
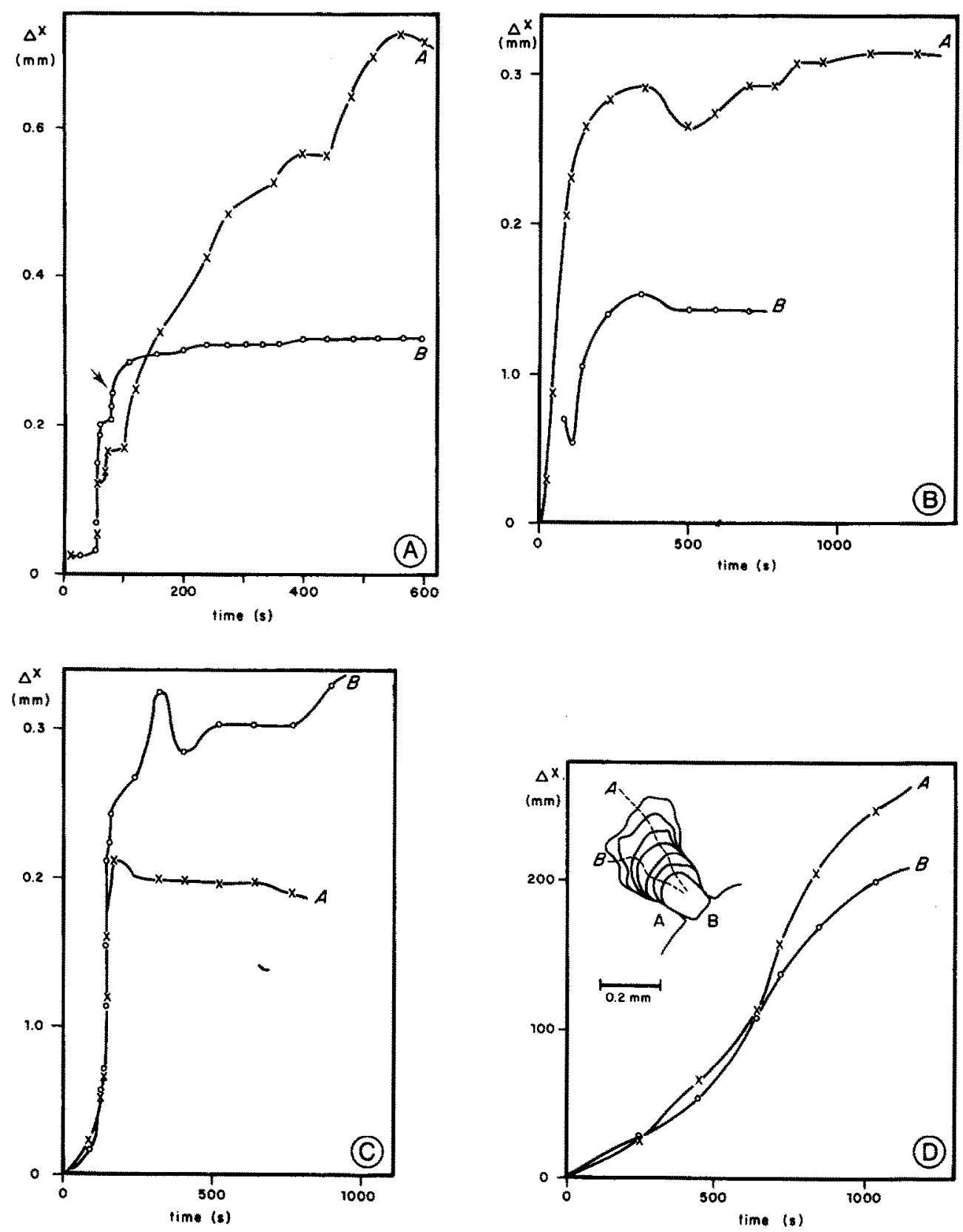

Fig. 9. A. Time-displacement curves of a grain boundary from Fig. 6, along selected orthogonal trajectories (shown as broken lines, at $320 \mathrm{~s}$ in Fig. 6). Note sudden changes in migration tate. Neighour switch along trajectory $B$ is indicated by arrow. $B$. Time-displacement curves of a grain boundary from Fig. 7, along selected orthogonal trajectories (shown as broken lines, at $5000 \mathrm{~s}$ in Fig. 7). C. Time-displacement curve of a grain boundary from Fig. 8., along selected orthogonal trajectories (shown as broken lines, at $6720 \mathrm{~s}$ in Fig. 8). D. Successive positions of a grain boundary and time-displacement curves along selected orthogonal trajectories. See text for discussion. 
plied by the solute escape model, suggesting a more complex process than was previously envisaged.

\section{Interpretation}

One of the questions arising from inspection of thin sections of samples deformed in a triaxial apparatus (Urai, 1983) is the extent to which metadynamic recrystallization has contributed to the microstructure. Besides showing that this effect is rather small, the above observations have provided useful insight into the details of the dynamic recrystallization process in general. Our understanding of the mechanisms of dynamic recrystallization comes almost exclusively from studies of materials containing "old" and "new" grains, i.e. of the first cycle of recrystallization. The present study has provided useful insights into the process of ongoing dynamic recrystallization and into the mechanisms by which a steady-state recrystallized microstructure can be maintained. Dynamic recrystallization of wet bischofite is a complicated process, involving significant contributions from both "slow" and "fast" grain boundary migration and from progressive misorientation of subgrains (see Urai et al., 1986). During this process, "new grains" are only formed by the pro- gressive misorientation of subgrains, grain boundary migration does not produce new grains sensu stricto (although material is constantly being renewed by the process). This continuous migration of grain boundaries typically results in grain scale processes like grain coalescence or dissection, cyclic changes in the size of an individual grain, and grain migration with respect to material points. Because the basic processes of dynamic recrystallization (grain boundary migration and progressive misorientation of subgrains) have been shown to operate in many minerals, the grain scale processes described above are likely to be common in the dynamically recrystallizing minerals, too. Reversals in grain boundary migration direction seem to be another common feature of the dynamic recrystallization process described above, and have also been reported in paradichlorobenżene (W.D. Means, pers. commun., 1984) and sodium nitrate (Tungatt and Humphreys, 1984). There can be several reasons why this happens. For example, ongoing deformation may cause a change in deformation pattern in two neighbouring grains, producing a reversal in driving force polarity. Another explanation, favored in the present case, goes as follows (see Fig. 10). Obviously, most grain boundary migration in the present experiments is driven by the energy decrease asso-
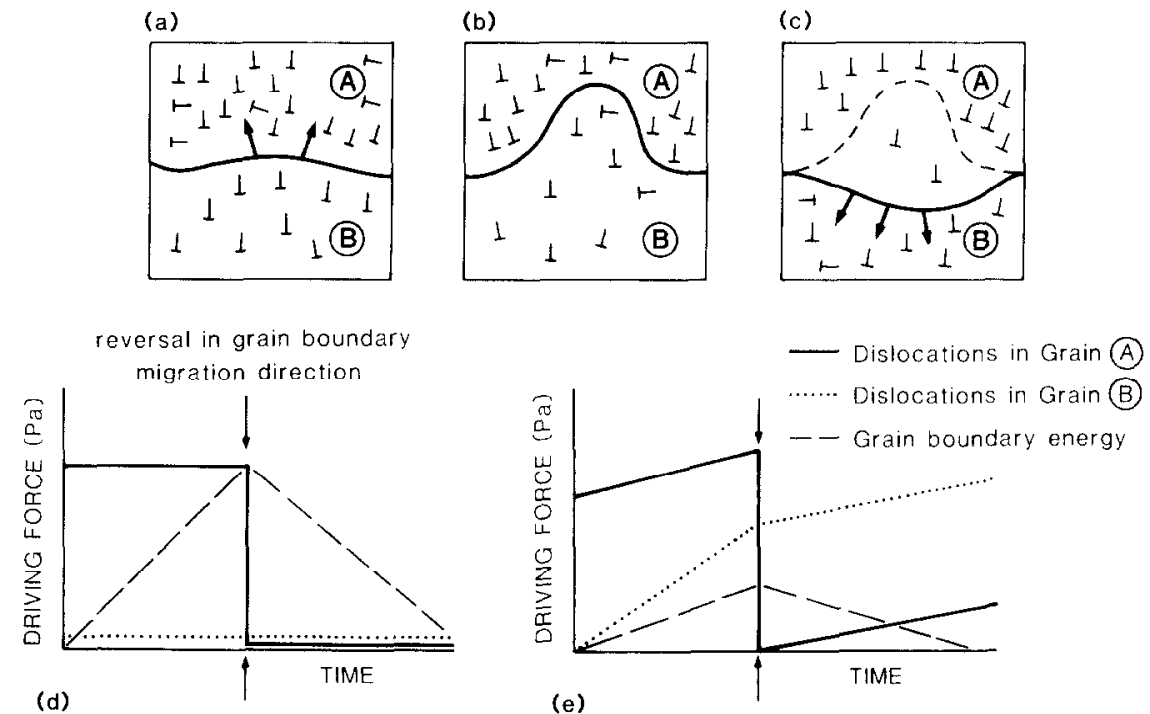

Fig. 10, a, b. c. Schematic diagram illustrating the reversals observed in grain boundary migration direction, during dynamic recrystallization d. Diagram illustrating the changes in driving force which accompany a reversal of grain boundary migration direction, in the static case (no deformation). e. Similar diagram as in d, but for the dynamic case. See text for discussion. 
ciated with the annihilation of dislocations. Under the present conditions of high temperature and high grain boundary mobility, this driving force can become comparable with the energy decrease available from reduction of the total grain boundary area (see Urai et al., 1986). Two possible situations are shown in Fig. 10. In the static case (Fig. 10d), the grain boundary bulging into grain $A$ is leaving strain-free material behind. After the bulge has locally developed a small enough radius of curvature, the driving force due to grain boundary energy can become equal to the driving force due to the presence of dislocations (but acting in the opposite direction), and the grain boundary migration direction can reverse. After the boundary has started to migrate in the reverse direction, material on both sides of it is essentially dislocation-free, and the only driving force present is the grain boundary energy, tending to straighten out the boundary.

During deformation, the process is somewhat more complicated (Fig. 10a, b, c and e). Here, new dislocations are constantly generated behind the migrating boundary. This will result in the boundary stopping at a larger radius of curvature than in the static case. Also, once the migration direction is reversed, the dislocations in grain $\mathrm{B}$ will provide an additional driving force to keep the boundary moving in this direction. The present experiments seem to support this explanation: in both the trajectories shown in Figs. 9a and d, the reversal indeed occurs toward the centre of curvature of the grain boundary. In Fig. $9 b$, the boundary is approximately straight. It should be noted however that the grain boundary bulge at which the reversal in migration direction nucleates can be smaller than the resolution of the time lapse photography $(\sim 0.01 \mathrm{~m})$ uscd in this work.

\section{Acknowledgments}

I wish to thank I.P. Poirier, G.S. Lister and W.D. Means for many discussions on dynamic recrystallization, and C.F. Woensdregt for permission to use the time-lapse cine apparatus. Drawings were prepared by S. Frans and H. Bliek; Vinod Kanhai did the word processing. Financial support from the Netherlands Organization for the Advancement of Pure Research (ZWO) is gratefully acknowledged.

\section{References}

Coelewij, P.A.J., Haug, G.M.W. and Van Kuijk, H., 1978. Magnesium salt exploration in the northeastern Netherlands. Geol. Mijnbouw, 57(4): 487-502.

Drury, M.R, Humphreys, F.J. and White, S., 1985. Large strain deformation studies using polycrystalline magnesium as a rock analogue. II. Dynamic recrystallization mechanism at high temperatures. Phys. Earth Planet. Inter., 40: 208-222

Haessner, F. and Hofmann, S., 1978. Migration of high angle grain boundaries. In: F. Haessner (Editor), Recrystallization of Metallic Materials. Riederer, Stuttgart, pp. 63-92.

Jessell, M.W., 1986. Grain boundary migration and fabric development in experimentally deformed octachloropropane. J. Struct. Geol., 8; 527-542.

Kern, H. and Franke, J.H., 1983. The effect of temperature on the chemical and mechanical behaviour of carnallite-halite rocks. Proc. 1st Conf. on the Mechanical Behaviour of Salt, Penn. State Univ., 1981. Trans. Tech. Publ., ClausthalZellerfeld., pp. 181-191.

Kern, H. and Franke, J.H., 1986. Carnallit-thermisches und thermomechanisches Verhalten in Endlager-Salzstöcken. Z. Dtsch. Geol. Ges., 137: 1-27.

Lister, G.S. and Dornsiepen, U.F., 1982. Fabric transitions in the Saxony Granulite terrian. J. Struct. Geol., 4: 81-92.

Means, W.D., 1981. The concept of steady-state foliation. Tectonophysics, 78: 179-201.

Means, W.D., 1983. Microstructure and micromotion in recrystallization flow of octachloropropane: a first look. Geol. Rundsch., 72(2): 511-528.

Poirier, J.P. and Guillope, M., 1979. Deformation induced recrystallization of minerals. Bull. Mineral., 102: 67-74.

Singh, V. Rao, P. and Taplin, D.M.R., 1973. On the role of grain boundary migration during the creep of zinc. $J$. Mater. Sci., 8: 373-381.

Tungatt, P.D. and Humphreys, F.J., 1981. An in-situ optical investigation of the deformation behaviour of sodium nitrate-an analogue for calcite. Tectonophysics, 78: $661-675$.

Tungatt, P.D. and Humphreys, F.J, 1984. The plastic deformation and dynamic recrystallization of polycrystalline sodium nitrate. Acta Metall., 32; 1625-1635.

Urai, J.L., 1983. Water assisted dynamic recrystallization and weakening in polycrystalline bischofite. Tectonophysics, 96 : 125-157.

Urai, J.L., 1985. Water-enhanced dynamic recrystallization and solution transfer in polycrystalline carnallite. Tectonophysics, 120: 285-317.

Urai, J.L. and Boland, J.N., 1985. Development of microstructure and the origin of hematite in naturally deformed carnallite. Neucs Jarhb. Mineral., Monatsh., 1985 (2): 58-72.

Urai, J.L., Humphreys, F.J. and Burrows, S.E., 1980. In-situ studies of the deformation and dynamic recrystallization of rhombohedral camphor. J. Mater. Sci., 15: 1231-1240.

Urai, J.L., Means, W.B. and Lister, G.S., 1986. Dynamic recrystallization of minerals. Geophys. Monogr., Am. Geophys. Union, 36 (The Paterson Vol.): 161-199. 